\title{
Controlled In Situ Gas Reaction Studies of Catalysts at High Temperature and Pressure with Atomic Resolution
}

\author{
L. F. Allard ${ }^{1}$, W. C. Bigelow ${ }^{2}$, S. Zhang ${ }^{2}$, X. Pan $^{2}$, Z. Wu ${ }^{1}$, S. H. Overbury ${ }^{1}$, W. B. Carpenter ${ }^{3}$, \\ F. S. Walden ${ }^{3}$, R. L. Thomas ${ }^{3}$, D. S. Gardiner ${ }^{3}$, B. W. Jacobs ${ }^{3}$, D. P. Nackashi ${ }^{3}$ and J. Damiano ${ }^{3}$ \\ 1. Physical Sciences Directorate, Oak Ridge National Laboratory, Oak Ridge, TN, USA. \\ 2. Dept. of Materials Science \& Engineering, University of Michigan, Ann Arbor, MI, USA. \\ 3. Protochips, Inc., Raleigh, NC, USA.
}

In situ reaction studies of catalyst materials using closed-cell environmental specimen holders have been shown to allow atomic resolution to be obtained on e.g. catalyst materials, at elevated temperatures and pressures [1-4]. These holders incorporate MEMS-based devices into the holder tip, which serve to encapsulate a gas layer between a thin film heater device and an ultra-thin amorphous SiN window. With a gas layer of only 5-10 $\mu \mathrm{m}$, pressures of up to $1 \mathrm{~atm}$ and temperatures of $1000^{\circ} \mathrm{C}$ are routinely employed without significant loss in resolution, especially in scanning transmission mode in a probecorrected microscope [1]. The holder-based approach does not require a dedicated TEM, and most existing microscopes are compatible with current holder designs.

By controlling the pressure and temperature, the gas cell can be run to closely mimic actual catalyst working conditions enabling in operando studies. Thus, new and more meaningful data can be gleaned from in situ experiments. The Protochips gas-cell system integrates mature ceramic thin film heating technology with a closed-cell design for ultra-stable, fast heating and quenching. The system includes fully automated, software-driven gas delivery, with real-time temperature compensation independent of gas species and pressures, in both static- and flowing-gas configurations. Figure 1 shows the interior configuration of the gas cell; 4 gold-plated electrical contacts are provided in a patent pending vacuumcompatible flexible circuit assembly; two are used for the power to the $2 \mathrm{~mm}$-square Aduro ${ }^{\mathrm{TM}}$ E-chip for this holder, as indicated by the dotted lines to the gold contacts on the heater. The design ensures easy electrical contact to the heating device and routine sealing of the cell against the high vacuum of the microscope column. A catalyst sample can be loaded onto the heater device and the cell assembled and made ready for insertion in a few minutes. Because the heater devices and $\mathrm{SiN}$ windows are fabricated on thin Si substrates, the overall thickness of the gas-cell assembly is $<1.25 \mathrm{~mm}$ (Fig. 2), which fits easily in the $2 \mathrm{~mm}$ gap of the JEOL URP pole piece. Figure 3 shows the portable gas delivery manifold; all routinely adjusted valves are electromechanically operated, via computer control. Provision is made for two experimental gas supply tanks, with a third tank typically used for nitrogen or argon gas purges.

Figures 4 and 5 illustrate the imaging capability achievable at low and high pressures in the cell, at elevated temperatures. Au nanoparticles on $\mathrm{CeO}_{2}$ nanorods shown in Fig. 4a,b show lattice and atomic columns in HAADF images, recorded at $5 \mathrm{Mx}, 300^{\circ} \mathrm{C}$, and at 300 and 600 Torr, respectively, in $4 \%$ $\mathrm{H}_{2} / \mathrm{Ar}$ reducing gas. Two sets of HAADF and BF image pairs of Ba-cerate catalyst support particles are shown in Fig. 5, originally recorded at $8 \mathrm{Mx}$ direct magnification, also in $4 \% \mathrm{H}_{2} / \mathrm{Ar}$ reducing gas. Pair $5 \mathrm{a}, \mathrm{b}$ was recorded with the cell at 35 Torr. The gas pressure was increased to 700 Torr for pair $5 \mathrm{c}$, d; it is clear that the near-atmospheric-pressure condition has little affect on the imaging of the crystal lattice. Details of other system features, and examples of in situ catalyst reactions will also be presented [5].

\section{References}

[1] LF Allard et al., Microsc. Microanal. 18 (2012), p. 656.

[2] Creemer, JF et al., Ultramicroscopy 108(9) (2008), p. 993.

[3] HL Xin, et al., Microsc Microanal 19 (2013), p. 1. 
[4] Yaguchi, T., et al., J Elect Microsc 60(3), 217-225.

[5] Microscopy research at ORNL sponsored by the U. S. Dept. of Energy, Office of Energy Efficiency and Renewable Energy, Vehicle Technologies Program, as part of the Propulsion Materials Program.
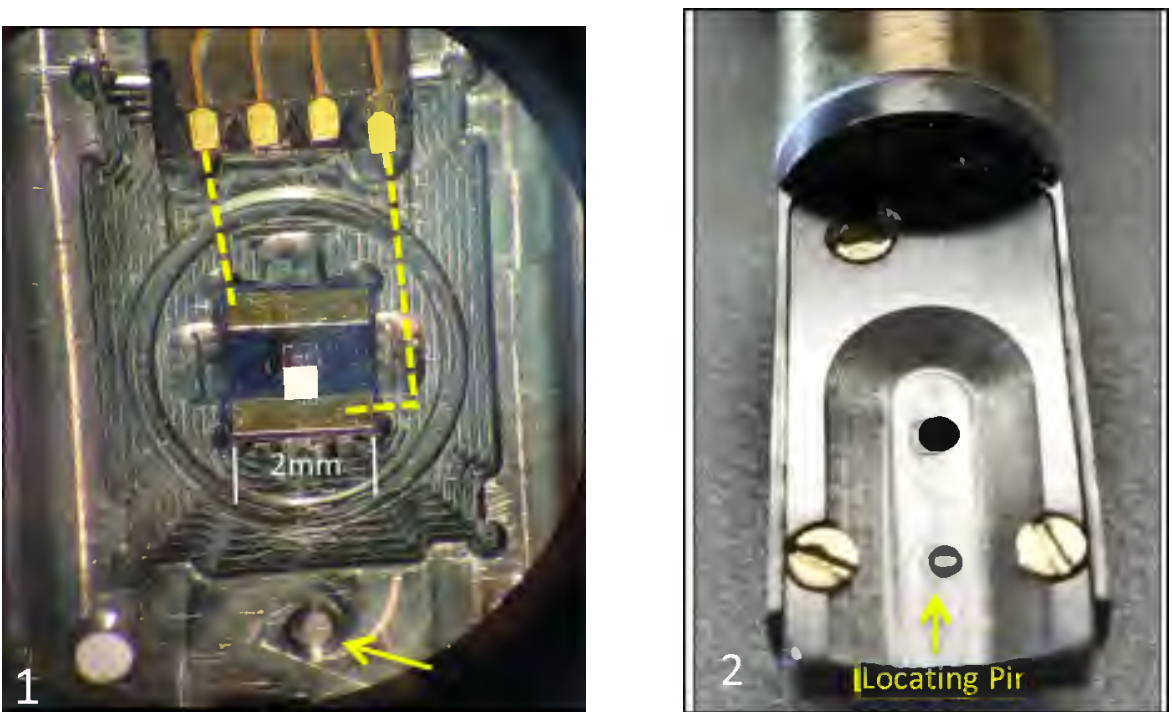

Figure 1. Interior view of the Gen 4 gas-cell holder, showing the Aduro heater, electrical contacts, and locating pin (arrow) for retainer plate of Fig. 2.

Figure 2. Tip of the gas cell holder, showing the retaining plate for the

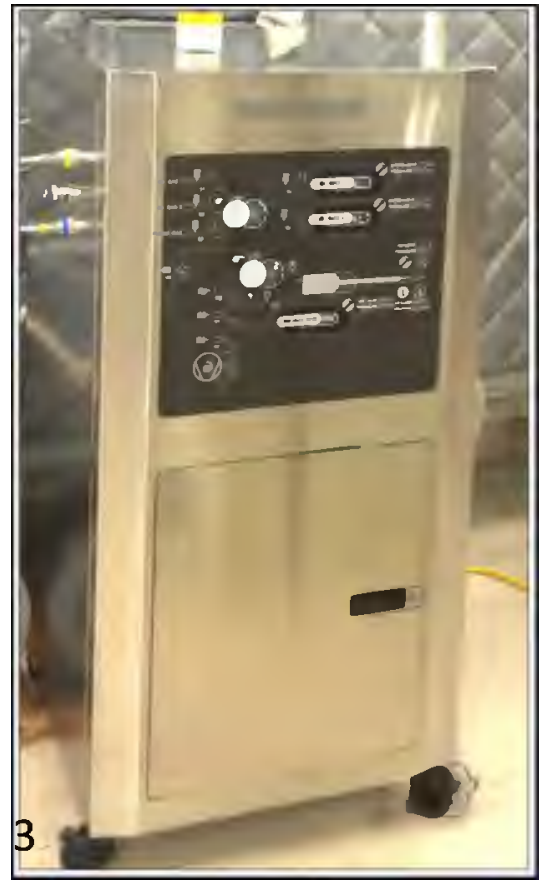
assembled cell, and the thin section to fit into the JEOL URP pole piece.

Figure 3. Gas-handling manifold supplies a purge gas and two experimental gases as desired, from stainless steel supply tanks via a computer-controlled valving system. A scroll pump is used for drypumping the cell and all stainless steel gas lines.
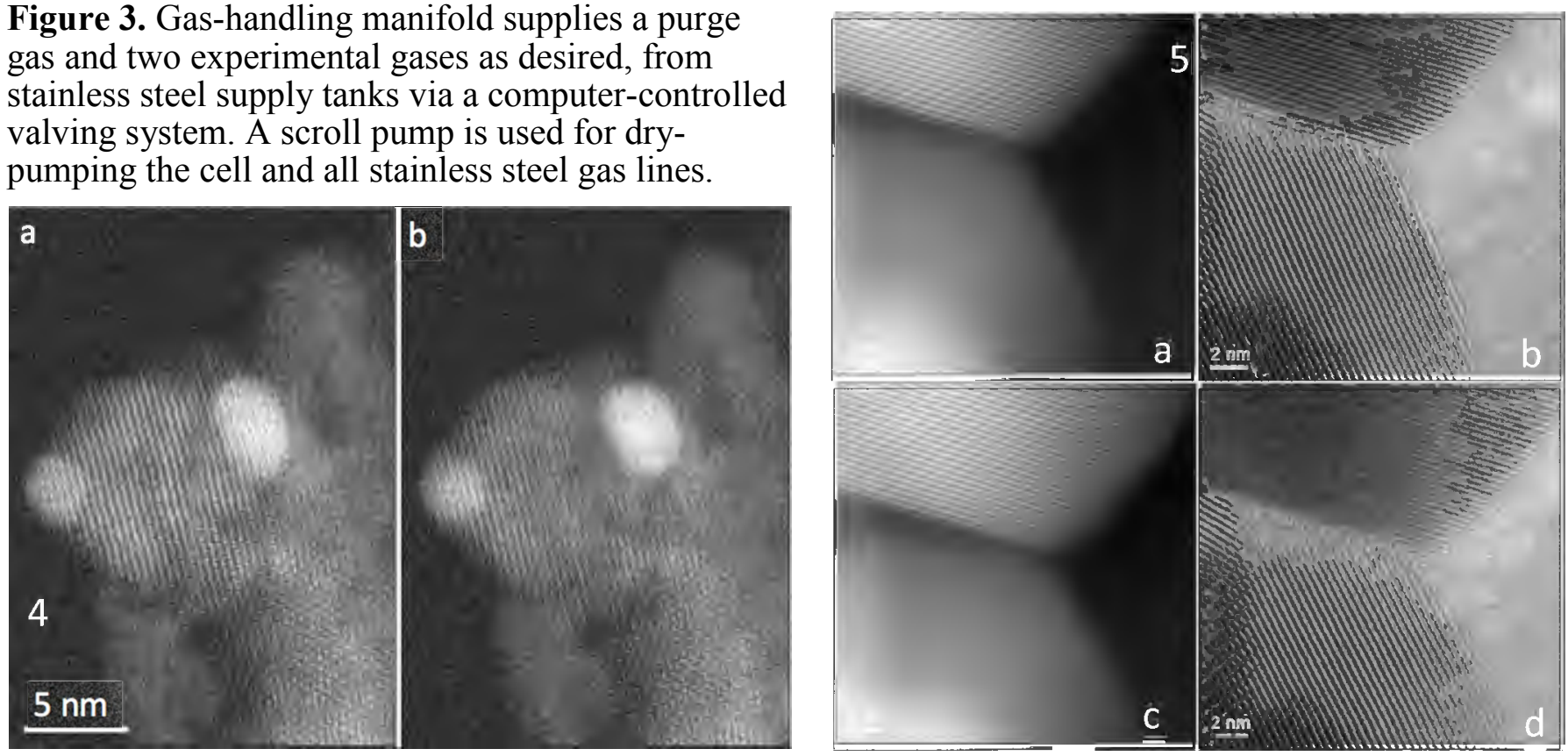

Figure 4. HAADF STEM images of Au nanoparticles on $\mathrm{CeO}_{2}$ nanorods, at $300^{\circ} \mathrm{C}$, a) 300 Torr, and b) 500 Torr.

Figure 5. a,b) $\mathrm{HAADF} / \mathrm{BF}$ image pair at 35 Torr reducing gas, and $500^{\circ} \mathrm{C}$, showing lattice in Ba-cerate particles; c,d) Same area at 700 Torr and $500^{\circ} \mathrm{C}$. No loss of resolution is seen at near-atmospheric pressure in the gas cell. 